Ciência Florestal, Santa Maria, v. 21, n. 2, p. 261-273, abr.-jun., 2011

\title{
ESTOQUES DE CARBONO E NITROGÊNIO NAS FRAÇÕES DA MATÉRIA ORGÂNICA EM ARGISSOLO SOB EUCALIPTO E PASTAGEM
}

\section{CARBON AND NITROGEN STOCKS IN ORGANIC MATTER FRACTIONS IN ALFISOL UNDER EUCALYPT AND PASTURE}

\author{
Rodinei Facco Pegoraro ${ }^{1}$ Ivo Ribeiro da Silva ${ }^{2}$ Roberto Ferreira de Novais ${ }^{3}$ \\ Nairam Felix de Barros $^{4}$ Sebastião Fonseca ${ }^{5}$ Carlos Silva Dambroz ${ }^{6}$
}

RESUMO

O cultivo de florestas plantadas de eucalipto em áreas de pastagem tem propiciado alterações no estoque de $\mathrm{C}$ e $\mathrm{N}$ no solo, em especial pelas diferentes características de cada planta e manejo dos resíduos vegetais; o eucalipto pode localizar maior estoque de $\mathrm{C}$ e $\mathrm{N}$ originário de resíduos da parte aérea na camada superficial do solo, e aumentar a relação $\mathrm{C} / \mathrm{N}$ dos resíduos vegetais em decomposição. Tais diferenças podem causar redução no estoque de $\mathrm{C}$ e $\mathrm{N}$ nas frações químicas, físicas e biológicas do solo, tanto nas frações mais lábeis, quanto nas mais recalcitrantes. Este trabalho teve como objetivo avaliar os estoques de C orgânico total (COT) e $\mathrm{N}$ total (NT), estoque de $\mathrm{C}$ e $\mathrm{N}$ nas substâncias húmicas (ácidos fúlvicos, húmicos e húminas), fração leve (C-MOL e N-MOL) e biomassa microbiana (C-BM e N-BM) em amostras de solos coletadas nas camadas de $0-0,10,0,10-0,20,0,20-0,40,0,40-0,60$ e $0,60-1,00 \mathrm{~m}$ de profundidade, na linha (EL) e entrelinha (EEL) do solo sob cultivo de eucalipto na quarta rotação com seis anos de idade, e em área de pastagem cultivada com brachiaria $(\mathrm{P})$. O estoque de carbono orgânico total e de carbono na fração leve do solo nas primeiras camadas do solo (até $0,60 \mathrm{~m}$ ) foi superior na entrelinha do eucalipto em comparação àquele cultivado com pastagem e na linha de cultivo do eucalipto, possivelmente favorecido pela incorporação de resíduos da colheita do ciclo anterior de eucalipto na atual entrelinha. Por meio da determinação da abundância natural de ${ }^{13} \mathrm{C}$ na camada de $0-0,20 \mathrm{~m}$ de solo verificou-se que 29 e 37\% do carbono presente na matéria orgânica do solo (MOS) após 28 anos de cultivo derivaram do eucalipto (planta $\mathrm{C}_{3}$ ), respectivamente, na linha e entrelinha, o que correspondeu à taxa de ciclagem média da MOS nesse solo de 1,04\% (linha) e 1,32\% (entrelinha) ao ano. No solo da entrelinha, observou-se que o $\mathrm{C}-\mathrm{C}_{3}$ proveniente do eucalipto incrementou o estoque de $\mathrm{C}$ orgânico do solo, mesmo com a substituição do $\mathrm{C}_{-} \mathrm{C}_{4}$ proveniente da pastagem, após 28 anos de cultivo do eucalipto. Para o nitrogênio nas substâncias húmicas, verificou-se estoques semelhantes entre o solo da entrelinha do eucalipto e o de pastagem, e superior ao do solo da linha do eucalipto, até $1 \mathrm{~m}$ de profundidade. O solo de eucalipto (EL e EEL) teve estoques de $\mathrm{C}$ e $\mathrm{N}$ na biomassa microbiana semelhante àquele cultivado com pastagem.

Palavras-chave: substâncias húmicas; abundância natural de ${ }^{13} \mathrm{C}$; fração leve; biomassa microbiana.

\footnotetext{
ABSTRACT

The cultivation of eucalypt in areas of pasture has resulted in changes of $\mathrm{C}$ and $\mathrm{N}$ storage in soil, mainly due

1. Engenheiro Agrônomo, Dr., Professor do Departamento de Ciências Agrárias, Universidade Estadual de Montes Claros, Av. Reinaldo Viana, Bico da Pedra s/n., CEP 39440-000, Janaúba (MG). Bolsista da FAPEMIG. rodinei.pegoraro@unimontes.br

2. Engenheiro Agrônomo, PhD., Professor do Departamento de Solos, Universidade Federal de Viçosa, Av. Peter Henry Rolfs, s/n., Campus Universitário, CEP 36570-000, Viçosa (MG). ivosilva@ufv.br

3. Engenheiro Agrônomo, PhD., Professor do Departamento de Solos, Universidade Federal de Viçosa, Av. Peter Henry Rolfs, s/n., Campus Universitário, CEP 36570-000, Viçosa (MG). Bolsista do CNPq. rfnovais@ufv.br

4. Engenheiro Florestal, PhD., Professor do Departamento de Solos, Universidade Federal de Viçosa, Av. Peter Henry Rolfs, s/n., Campus Universitário, CEP 36570-000, Viçosa (MG). Bolsista do CNPq. nfbarros@ufv.br

5. Engenheiro Florestal, MSc., Pesquisador da Aracruz Celulose S.A., Rod. Aracruz, B. Riacho, CEP 29192-000, Aracruz (ES).sf@aracruz.com.br

6. Estudante de Engenharia Florestal, Universidade Federal de Viçosa, Av. Peter Henry Rolfs, s/n., Campus Universitário, CEP 36570-000, Viçosa (MG). csdenf@yahoo.com.br

Recebido para publicação em 29/10/2009 e aceito em 08/06/2010
} 
to the different characteristics of each plant and their biomass management; the largest stock of $\mathrm{C}$ and $\mathrm{N}$ can be found under eucalypt, originating from the biomass at the soil surface layer and increasing the $\mathrm{C} / \mathrm{N}$ in decomposition of plant residues. These differences may cause a decrease in the storage of $\mathrm{C}$ and $\mathrm{N}$ fractions in the chemical, physical and biological soil, both in the more labile, an the more recalcitrant fractions. This study aimed to evaluate the stocks of total organic carbon (TOC) and total N (TN), the stock of C and $\mathrm{N}$ in humic substances (fulvic acids, humic and humin), the light fraction (C-MOL and N-MOL) and the microbial biomass (C-BM and N-BM) in samples of collected from the layers 0-0.10, 0.10-0.20, 0.20-0.40, 0.40-0.60 and 0.60-1.00 $\mathrm{m}$ in depth, line (EL) and interline (EEL) from the soil under eucalypt in the fourth rotation with six years of age, and from an area of cultivated pasture with Brachiaria (P). The total organic carbon stock and carbon in the light fraction in the first layers of soil $(0.60 \mathrm{~m})$ was higher in the interline of eucalypt compared with that from the cultivated pasture and the line of eucalypt, probably favored by harvest residue from the previous cycle of eucalypt buried in the current interline. By determining the natural abundance of ${ }^{13} \mathrm{C}$ in the $0-0.20 \mathrm{~m}$ soil, it was found that $29 \%$ and $37 \%$ of carbon present in the soil organic matter (SOM) after 28 years of cultivation in the line and interline, respectively, was derived from eucalypt $\left(\mathrm{C}_{3}\right.$ plants), which corresponded to an average rate of cycling of SOM in this soil of $1.04 \%$ (line) and $1.32 \%$ (interline) per year. In the soil interline it was observed that the $\mathrm{C}-\mathrm{C}_{3}$ from the eucalypt increased the stock of soil organic $\mathrm{C}$, even with the replacement of $\mathrm{C}-\mathrm{C}_{4}$ from the pasture, after 28 years of eucalypt cultivation. For nitrogen in humic substances, a similar stock was obtained for the soil of the interline of eucalypt and that of the pasture, which was higher than that of the soil line of eucalypt, up to $1 \mathrm{~m}$ deep. The soil of eucalypt (EL and EEL) showed a stock of $\mathrm{C}$ and $\mathrm{N}$ in microbial biomass similar to that of cultivated pasture.

Keywords: humic substances; natural abundance of ${ }^{13} \mathrm{C}$; light fraction; microbial biomass.

\section{INTRODUÇÃO}

O cultivo de eucalipto em áreas de pastagem pode causar mudanças no estoque de $\mathrm{C}$ e $\mathrm{N}$ no solo e, possivelmente, alterar a qualidade da matéria orgânica do solo (MOS). Florestas plantadas de eucalipto são capazes de alocar maior conteúdo de $\mathrm{Ce} \mathrm{N}$ na sua parte aérea. Ganhos de $\mathrm{C}$ no solo, derivados do eucalipto, concentram-se na camada de 0-0,30 m (BINKLEY et al., 2004), enquanto outras culturas como as pastagens caracterizam-se por estocar mais $\mathrm{C}$ no seu sistema radicular (ALCÂNTARA et al., 2004) (cerca de 30 a $50 \%$ do $C$ fixado via fotossíntese) a maiores profundidades (KUZYAKOV e DOMANSKI, 2000) que no solo com eucalipto. Com isso, o ganho em conteúdos de $\mathrm{C}$ e $\mathrm{N}$ nas camadas superficiais do solo pela instalação dessa espécie arbórea pode ser contrabalançado por perdas de $\mathrm{C}$ da cultura anterior nas camadas inferiores (BINKLEY e RESH, 1999; BINKLEY et al., 2004), embora exista controvérsia dos resultados verificados na literatura (LIMA, 2004).

Comparativamente, maiores perdas de $\mathrm{C}$ no solo ocorreram quando cultivos de Pinus foram instalados em solos de pastagem (NEUFELDT et al., 2002), e maiores ganhos quando espécies fixadoras de $\mathrm{N}_{2}$ foram estabelecidas sobre o solo de pastagem (PAUL et al., 2002). Em vasta revisão de literatura,
Guo e Gifford (2002) reportaram 74 publicações para indicar que estoques de $\mathrm{C}$ no solo decrescem após mudanças no uso do solo de pastagem para cultivos arbóreos (-10\%) e de pastagem para cultivos anuais $(-59 \%)$. Já cultivos de eucalipto em solos degradados de pastagem do Brasil têm levado a incrementos substanciais no estoque de $\mathrm{C}$ em curtos períodos de tempo (30 anos) (LIMA et al., 2006). Possivelmente, aumentando os estoques de $\mathrm{C}$ e $\mathrm{N}$ nas frações mais lábeis da MOS e a produtividade (sustentabilidade) do sistema a longo prazo. Além de cultivos de eucalipto, Lilienfein e Wilcke (2003) concluíram que o cultivo de Pinus tem incrementado substancialmente os estoques de $\mathrm{C}$ no ecossistema, especialmente pelo aumento no estoque de $\mathrm{C}$ na parte aérea, pois os estoques de $\mathrm{C}$ no solo foram semelhantes nas camadas de $0-0,3 \mathrm{~m}$ aos do solo de pastagem degradada.

Estoques de $\mathrm{C}$ e $\mathrm{N}$ na fração leve da MOS aumentaram na superfície $(0-0,10 \mathrm{~m})$ do solo cultivado com eucalipto após a pastagem, porém a mudança no uso não influenciou no estoque de $\mathrm{C}$ na biomassa microbiana do solo com o aumento do tempo de cultivo (LIMA et al., 2006). No entanto, pastagens mais produtivas (maior produção de fitomassa) podem possibilitar incrementos no teor de $\mathrm{C}$ nas frações mais lábeis e recalcitrantes na MOS e nos teores de $\mathrm{N}$ no solo.

Ci. Fl., v. 21, n. 2, abr.-jun., 2011 
Frações mais recalcitrantes da MOS, como as substâncias húmicas, são as menos responsivas à alterações no uso do solo, mas apresentam os maiores tempos médios de residência no solo (ROVIRA e VALLEJO, 2002), o que possibilitaria maior estocagem desses elementos no ecossistema. O cultivo de eucalipto pode incrementar os estoques de $\mathrm{C}$ nessas frações por causa da maior deposição de resíduos lignificados de mais difícil decomposição.

A utilização de gradagem "bedding" para preparo do solo e incorporação de resíduos culturais após o corte das árvores foi uma prática cultural muito comum entre cultivos comerciais de florestas de eucalipto num passado recente. Com esse preparo se buscava favorecer o próximo plantio na entrelinha de onde foram cortadas as árvores. Essa prática favorece maior acúmulo de resíduos na região onde estão localizadas as cepas, podendo, ao longo do tempo, incrementar o conteúdo de $\mathrm{C}$ e $\mathrm{N}$ no solo. No entanto, poucos estudos foram realizados para verificar essa hipótese.

Nesse sentido, o presente estudo teve o objetivo de avaliar os estoques de $\mathrm{C}$ e $\mathrm{N}$ nas frações lábeis e substâncias húmicas em solos cultivados com eucalipto (linha e entrelinha) e pastagem cultivada.

\section{MATERIAL E MÉTODOS}

$\mathrm{O}$ estudo foi conduzido em cultivos comerciais de eucalipto e pastagem no município de Aracruz, região litorânea doe estado do Espírito Santo, localizada a $19^{\circ} 48^{\prime}$ e $40^{\circ} 17^{\prime}$ W. O clima da região é Aw, segundo a classificação de Köppen (OMETTO, 1981), com temperatura e precipitação média anual de, respectivamente, $23{ }^{\circ} \mathrm{C}$ e 1.400 $\mathrm{mm} \mathrm{ano}^{-1}$. Foram selecionadas áreas cultivadas com pastagem de Brachiaria brizantha, que havia sido plantada há pelo menos cinco décadas e, adjacente a essa área, em sucessão à pastagem, um talhão de eucalipto com 6 anos de idade, historicamente cultivado por quatro rotações (28 anos).

$O$ local representa uma microbacia típica da região, sendo o solo caracterizado como um Argissolo Amarelo fase floresta tropical subperenifólia, textura média/argilosa, derivado do grupo Barreiras. Previamente ao plantio do eucalipto, a área foi colhida e reformada, ocasião em que o solo foi preparado mediante gradagem ('bedding'), coveado e fertilizado com $100 \mathrm{~g} \mathrm{cova}^{-1}$ do formulado NPK 6-30-6. O plantio das mudas de eucalipto foi realizado em 1998, com mudas clonais provenientes do híbrido: Eucalyptus grandis $\mathrm{x}$
Eucaliptus urophyla, com espaçamento de $3 \times 3 \mathrm{~m}$. Após 90 dias do plantio, os clones receberam 350 $\mathrm{kg} \mathrm{ha}^{-1}$ de fosfato natural e, no final do primeiro ano, mais $160 \mathrm{~kg} \mathrm{ha}^{-1}$ de NPK 6-30-6.

Os tratamentos consistiram de: P (Solo de pastagem de Brachiaria brizantha); EL (Solo de eucalipto, com amostras coletadas na linha de plantio atual) e EEL (Solo de eucalipto, com amostras coletadas na entrelinha de plantio atual). Nessas áreas com diferentes tipos de uso, foram selecionados talhões de aproximadamente 25 ha onde se coletaram, na linha e entrelinha do eucalipto e na área de pastagem, amostras compostas (quatro amostras simples) nas camadas de $0-0,10,0,10-0,20$, $0,20-0,40,0,40-0,60$ e $0,60-1,00 \mathrm{~m}$. Em cada talhão, foram abertas trincheiras com $1,3 \mathrm{~m}$ de profundidade e, então, em cada camada média foram coletadas amostras deformadas e indeformadas com anéis volumétricos para determinar a densidade do solo. A coleta de amostras na linha e entrelinha do solo sob cultivo de eucalipto é justificada pela utilização de grade "bedding" para preparo do solo nos cultivos anteriores, a qual incorpora e cobre com solo os resíduos da colheita que foram alocados para a linha de cepas (atual entrelinha).

As amostras de solo foram coletadas na época chuvosa (janeiro/fevereiro de 2005). Depois de coletadas, as amostras de solo foram imediatamente secadas ao ar, destorroadas, passadas por peneira com malha de $2 \mathrm{~mm}$, homogeneizadas e subamostras foram retiradas para caracterização química, enquanto as amostras indeformadas foram encaminhadas à estufa para determinação da densidade do solo. Os resultados para a área de pastagem foram os seguintes: $\mathrm{pH}\left(\mathrm{H}_{2} \mathrm{O}\right)=5,7 ; \mathrm{Ca}^{2+}=1,4 \mathrm{cmol}_{\mathrm{c}} \mathrm{dm}^{-3} \mathrm{e} \mathrm{Mg}^{2+}=0,4$ $\mathrm{cmol}_{\mathrm{c}} \mathrm{dm}^{-3}\left(\mathrm{KCl}-1 \mathrm{~mol} \mathrm{~L}^{-1}\right) ; \mathrm{H}+\mathrm{Al}=2,2 \mathrm{cmol}_{\mathrm{c}} \mathrm{dm}^{-3}$ (acetato de cálcio $\left.0,5 \mathrm{~mol} \mathrm{~L}^{-1}-\mathrm{pH} 7,0\right) ; \mathrm{P}=1,1 \mathrm{mg}$ $\mathrm{dm}^{-3} ; \mathrm{K}=13,0 \mathrm{mg} \mathrm{dm}^{-3}$ (Mehlich 1); densidade do solo $=1,5 \mathrm{Mg} \mathrm{m}^{-3}$. Para a área de eucalipto (média de EL e EEL) obteve-se os seguintes valores: $\mathrm{pH}\left(\mathrm{H}_{2} \mathrm{O}\right)$ $=5,4 ; \mathrm{Ca}^{2+}=1,5 \mathrm{cmol}_{\mathrm{c}} \mathrm{dm}^{-3} \mathrm{e} \mathrm{Mg}^{2+}=0,5 \mathrm{cmol}_{\mathrm{c}} \mathrm{dm}^{-3}$ $\left(\mathrm{KCl}-1 \mathrm{~mol} \mathrm{~L}^{-1}\right) ; \mathrm{H}+\mathrm{Al}=4,3 \mathrm{cmol}_{\mathrm{c}} \mathrm{dm}^{-3}$ (acetato de

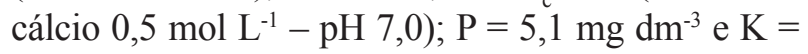
$34,0 \mathrm{mg} \mathrm{dm}^{-3}$ (Mehlich 1) e densidade do solo $=1,4$ $\mathrm{Mg} \mathrm{\textrm {m } ^ { - 3 }}$.

Em todas as amostras coletadas, foram efetuadas análises de carbono orgânico total (COT), nitrogênio total (NT), C e N das substâncias húmicas: frações ácidos fúlvicos, ácidos húmicos, huminas e o somatório das três frações (substâncias húmicas$\mathrm{SH}$ ). Também foram feitas determinações do $\mathrm{C}$ e $\mathrm{N}$ da matéria orgânica leve (C-MOL e N-MOL), C 
da biomassa microbiana (C-BM) e $\mathrm{N}$ da biomassa microbiana (N-BM).

\section{Determinação do carbono orgânico total e nitrogênio total do solo}

Amostras de solo (TFSA) foram trituradas e passadas em peneira de 100 mesh $(0,149 \mathrm{~mm})$ para determinação de COT pelo método de oxidação via úmida, com aquecimento externo (YEOMANS e BREMNER, 1988). O NT foi determinado por destilação após digestão sulfúrica (BATAGLIA et al., 1983).

\section{Fracionamento de substâncias húmicas}

O fracionamento de substâncias húmicas foi realizado segundo o método sugerido pela International Humic Substances Society (SWIFT, 1996). Desse fracionamento, obtiveram-se as frações ácidos fúlvicos (FAF), ácidos húmicos (FAH) e huminas $(\mathrm{FH})$. Do somatório de todas essas frações húmicas, foram obtidas as substâncias húmicas (SH). A determinação de $\mathrm{C}$ e $\mathrm{N}$ em cada fração húmica foi realizada pelo método de oxidação via úmida, respectivamente com aquecimento externo (YEOMANS e BREMNER, 1988) e por destilação após digestão sulfúrica (BATAGLIA et al., 1983), respectivamente.

\section{Separação da matéria orgânica leve (MOL) e quantificação do carbono (C-MOL) e nitrogênio (N-MOL)}

O método adotado foi descrito por Sohi et al. (2001) e consistiu em agitar manualmente $13 \mathrm{~g}$ de amostra de solo seco e peneirado $(2 \mathrm{~mm})$, provenientes das diferentes camadas, com $30 \mathrm{~mL}$ de iodeto de sódio (densidade $1,8 \mathrm{~kg} \mathrm{~L}^{-1}$ ) em tubo de 50 $\mathrm{mL}$ de centrífuga. Em seguida, as amostras foram centrifugadas a $2.400 \mathrm{~g}$ por $15 \mathrm{~min}$, e o material orgânico sobrenadante foi coletado em peneira de 100 mesh, o qual constituiu a fração da matéria orgânica leve (MOL). Os teores de $\mathrm{C}$ e $\mathrm{N}$ na fração leve foram determinados por combustão via seca em analisador elementar CHNS (Perkin Elmer CHNS/ O 2400).

\section{Determinação do carbono e nitrogênio da biomassa microbiana do solo}

Amostras de solo (TFSA) foram pesadas e acondicionadas em copos plásticos com tampas perfuradas e incubadas com umidade a $60 \%$ da capacidade de campo $(-33 \mathrm{kPa})$ em ambiente controlado sob temperatura de $20^{\circ} \mathrm{C}$ por 10 dias, para permitir o restabelecimento da comunidade microbiana. Findo o período de incubação, procedeuse à determinação do $\mathrm{C}$ da biomassa microbiana $(\mathrm{C}$ $\mathrm{BM}$ ) pelo método da irradiação e extração (ISLAM e WEIL, 1998) e, do N da BM (N-BM) por destilação após digestão sulfúrica (BATAGLIA et al., 1983). Os estoques de $\mathrm{C}$ e $\mathrm{N}$ do solo foram estimados por meio da seguinte equação:

$$
\mathrm{C}=\mathrm{CO} \times \mathrm{Ds} \times \mathrm{E}
$$

Em que: $\mathbf{C}$ é o estoque de $\mathrm{C}$ orgânico na camada de solo (t ha $\left.{ }^{-1}\right)$, CO é o teor de C orgânico total na camada de solo (dag kg-1), Ds é a densidade do solo na camada de solo $\left(\mathrm{Mg} \mathrm{m}^{-3}\right)$ e $\mathbf{E}$ é a espessura da camada amostrada $(\mathrm{cm})$

$\mathrm{O}$ estoque de $\mathrm{C}$ e $\mathrm{N}$ para cada camada de solo foi obtido pela multiplicação da percentagem de C pela massa de solo de cada camada com o volume de solo encontrado em cada camada (ex.: 0-0,10 m) e em relação sua densidade $\left(\mathrm{Mg} \mathrm{m}^{-3}\right)$, obtendo-se ao final, o somatório do estoque de $\mathrm{C}$ na camada de 0-1 m. Foi realizada a correção da densidade do solo entre cada comparação de tratamentos segundo Sisti et al. (2004), utilizando-se o tratamento com menor densidade do solo (EL) como condição-padrão.

\section{Determinação da abundância natural de ${ }^{13} \mathrm{C}$ do solo}

Para a análise da abundância natural do ${ }^{13} \mathrm{C}$, as amostras de solo da camada de $0-0,10 \mathrm{~m}$ foram passadas em peneira de 100 mesh $(0,149 \mathrm{~mm})$ e a relação ${ }^{13} \mathrm{C} /{ }^{12} \mathrm{C}$ foi medida em espectrômetro de massa de razão isotópica de fluxo contínuo (20-20 Anca-GLS, Sercon, Crewe, UK). A razão isotópica foi expressa em partes por $1.000 \%$, em relação ao padrão de Pee Dee Belemnita (PDB). O compartimento de $\mathrm{C}$ derivado da pastagem $\left(\mathrm{C}_{4}\right)$ foi calculado conforme Vitorello et al. (1989):

$$
\% C_{4}=\frac{\delta-\delta_{s}}{\delta_{p}-\delta_{s}}
$$

Em que $\boldsymbol{\delta}$ é a abundância natural do ${ }^{13} \mathrm{C}$ nas amostras e solo (pastagem), $\boldsymbol{\delta}_{\mathrm{s}}$ é abundância natural do ${ }^{13} \mathrm{C}$ nas amostras de solos sem nenhuma contribuição das plantas $\mathrm{C}_{4}$ (mata nativa), $\boldsymbol{\delta}_{\mathrm{p}}$ é abundância natural do ${ }^{13} \mathrm{C}$ nas amostras das plantas $\mathrm{C}_{4}$ (pastagem). Os valores de $\delta_{\mathrm{p}}$ e $\delta_{\mathrm{s}}$ foram determinados em amostras de material vegetal de pastagem e na camada de 0-0.20 m de solo sob floresta coletados de áreas próximas entre si e dos povoamentos de eucalipto. A contribuição percentual do $\mathrm{C}$ orgânico originário das 
plantas $\mathrm{C}_{3}$ (Mata nativa) foi calculada como $\% C_{3}=$ $100-\% C_{4}$.

Em virtude da substituição cronológica de usos do solo (mata nativa precedendo pastagem e eucalipto) assumiu-se que o $\mathrm{C}-\mathrm{C}_{3}$ de carbono do solo derivado de mata nativa após 54 anos de desmatamento e uso de pastagem, a taxa de mudança de $\mathrm{C}-\mathrm{C}_{3}$ na MOS não seria alta. Assim, manteve-se constante a proporção $\mathrm{C}-\mathrm{C}_{3}$ na camada de $0-0,20$ $\mathrm{m}$ de solo e, considerou-se que qualquer aumento na contribuição do $\mathrm{C}-\mathrm{C}_{3}$ para o carbono orgânico do solo seria decorrente da deposição de carbono de plantas de eucalipto $\left(\mathrm{C}_{3}\right)$. Obviamente, por meio dessas afirmativas, podem ser subestimadas perdas de $\mathrm{C}-\mathrm{C}_{3}$ de floresta nativa $\left(\mathrm{C}_{3}\right)$ para a MOS no período de cultivo do eucalipto, no entanto, essa técnica de abordagem foi adotada por Binkley et al. (2004) em estudo de sucessão de cultivos de canade-açúcar para eucalipto (primeira rotação) no Havaí. Assim, a contribuição do eucalipto $\mathrm{C}_{3}$ para a MOS foi calculado com base na equação:

$$
\% C_{E}=100-\% C\left(C_{4}\right)-\% C\left(C_{3 M N}\right)
$$

Em que: $\% \mathbf{C}_{\mathbf{E}}$ é a proporção de carbono orgânico derivado do eucalipto, $\% \mathbf{C}\left(\mathbf{C}_{4}\right)$, é a proporção de carbono orgânico proveniente da pastagem e, $\mathbf{C}\left(\mathbf{C}_{3 \mathbf{M N}}\right)$ é a proporção de carbono orgânico derivado da mata nativa. E o estoque carbono orgânico ( $\mathrm{t} \mathrm{ha} \mathrm{h}^{-1}$ ) derivado do eucalipto foi calculado por meio da seguinte equação:

$$
C_{E}=C t-C_{3 M N}-C_{4}
$$

Em que: $\mathbf{C}_{\mathbf{E}}$ é o estoque de carbono orgânico derivado do eucalipto, $\mathbf{C t}$ é o estoque total de carbono orgânico na camada de 0-0,20m de solo de eucalipto, $\mathbf{C}_{3 \text { MN }}$ é o estoque de carbono orgânico derivado da mata nativa (plantas $\mathrm{C}_{3}$ ) observado no momento da substituição de cultivos (pastagem-eucalipto) e $\mathbf{C}_{4}$ é o estoque de carbono orgânico derivado de plantas $\mathrm{C}_{4}$ (pastagem) no solo de eucalipto.

\section{Análise estatística}

Os resultados foram analisados no programa estatístico SAEG 5.0 (FUNARBE, 1993). O delineamento experimental foi em blocos inteiramente casualizados, sendo os usos do solo alocados na parcela principal e as camadas de solo nas subparcelas. O teste de médias adotado foi o LSD de Fischer ( $\mathrm{P}<5 \%$ ) protegido (STEEL et al., 1997), ou seja, foram realizadas comparações múltiplas apenas quando o teste de $\mathrm{F}$ da análise de variância foi significativo $(\mathrm{P}<5 \%)$

\section{RESULTADOS E DISCUSSÃO}

\section{Estoques de carbono e nitrogênio total e nas frações das substâncias húmicas}

Para a camada de 0-0,10 m, na entrelinha da área do eucalipto, verificou-se maior estoque de COT (Figura 1), condição não observada para os estoques de $\mathrm{C}$ nas substâncias húmicas $(\mathrm{P}>5 \%)$ entre os cultivos e locais de amostragem (linha e entrelinha de eucalipto), inferindo que boa parte do incremento de COT verificado na entrelinha do eucalipto pode ter advindo do maior estoque de $\mathrm{C}$ na fração leve (Figura 3). Possivelmente, esses resultados estejam associados à maior deposição de resíduos da colheita sobre as cepas cortadas no tratamento EEL e, posteriormente, enterradas pela utilização de grade "bedding" no preparo do solo para plantio das mudas, juntamente com a morte e decomposição radicular, incrementando a MOS nesse local, já que a coleta das amostras de solo foi realizada seis anos após o corte das árvores da rotação anterior. Estudos realizados com crescimento de raízes in situ indicaram que a contribuição relativa de raízes para o carbono orgânico do solo foi em média 2 vezes maior que da parte aérea, variando de 1,5 a 3,7\% (RASSE et al., 2005). As raízes apresentam maior proporção de tecidos lignificados do que a serapilheira da parte aérea do eucalipto, o que reduz o seu coeficiente de decomposição "k” no solo (LEMMA et al., 2007).

Solos de clima tropical cultivados com florestas apresentam grande potencial de estocagem de $\mathrm{C}$ em comparação às pastagens pouco produtivas. Silver et al (2000) verificaram em sua revisão uma taxa de acúmulo de $\mathrm{C}$ em solos reflorestados sobre pastagem de $0,41 \mathrm{t} \mathrm{ha}^{-1}$ ano $^{-1}$ num período de 100 anos e destacam o potencial de incremento de $\mathrm{C}$ estocado na fitomassa de $6 \mathrm{t} \mathrm{ha}^{-1}$ ano $^{-1}$ num período de 20 anos.

Nas camadas de 0,20-0,40 e 0,40-0,60 $\mathrm{m}$, foram encontradas as maiores diferenças entre cultivos para os estoques de $\mathrm{C}$ nas substâncias húmicas, sendo na entrelinha do eucalipto novamente superior aos demais. Resultado semelhante foi observado para os estoques de $\mathrm{N}$ total e nas substâncias húmicas partindo da camada de 0,20-0,40 m (Figura 2). Em virtude da incorporação dos resíduos de eucalipto do cultivo anterior na entrelinha, propiciando maior aporte de compostos carbonados e nitrogenados, estocou-se mais $\mathrm{C}$ na maioria das frações húmicas (FAF, FAH e FH) na camada de 0,20-0,40 m (Figura 2). 


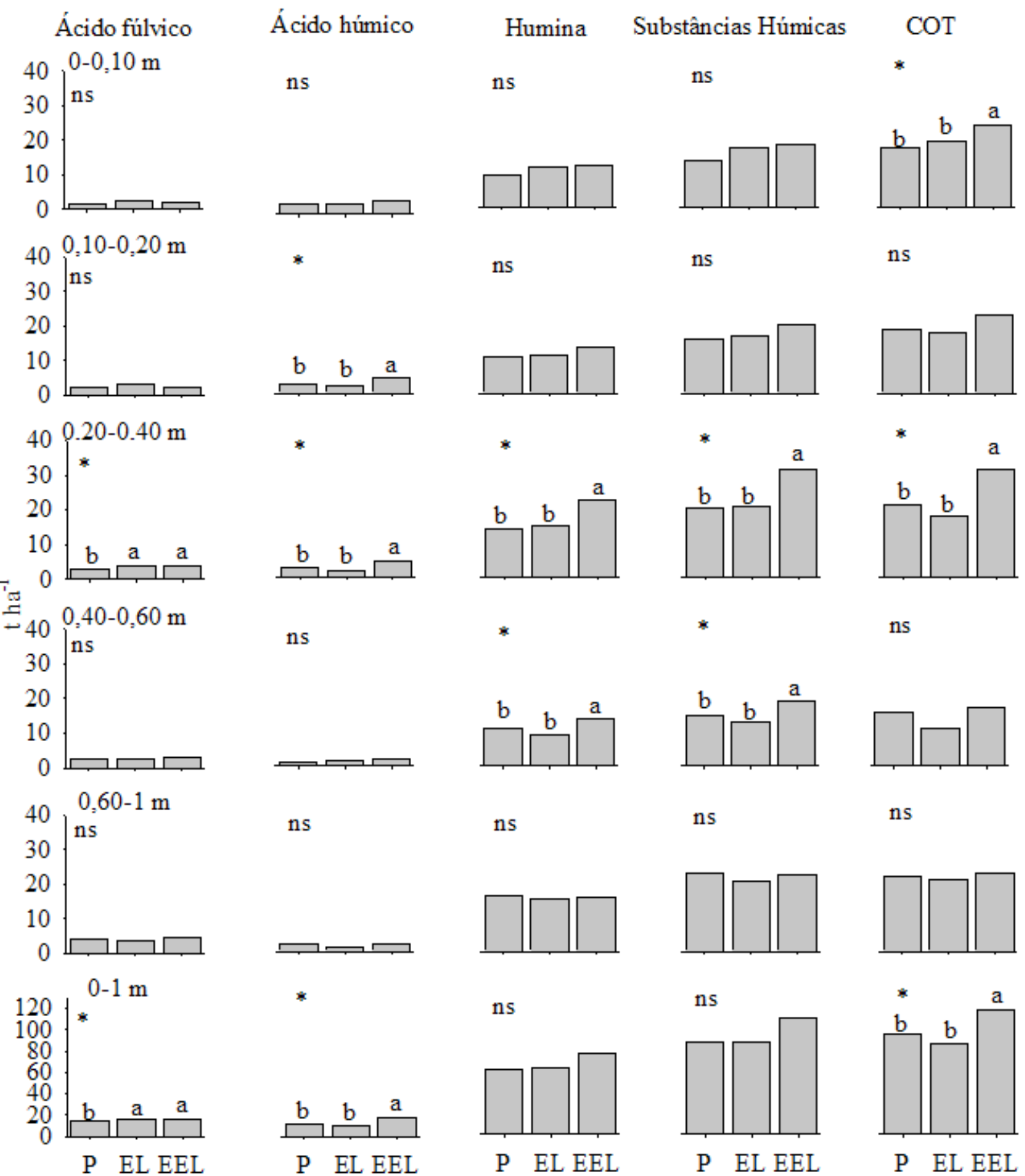

FIGURA 1: Estoques de carbono orgânico total (COT), C nas frações das substâncias húmicas (ácidos fúlvicos, húmicos e húminas) e total (substâncias húmicas) nas camadas de $0-0,10 ; 0,10$ 0,$20 ; 0,20-0,40 ; 0,40-0,60 ; 0,60-1$ e $0-1 \mathrm{~m}$ de solo, em amostras coletadas nas linhas (EL) e entrelinhas (EEL) do eucalipto e pastagem (P). Médias seguidas da mesma letra minúscula não diferem entre si a $5 \%$ pelo teste $\mathrm{LSD}$. ${ }^{*}$, ns: respectivamente significativo a $5 \%$ e não significativo $(\mathrm{P}>5 \%)$ para cultivos, pelo teste $\mathrm{F}$ da ANOVA.

FIGURE 1: Total organic carbon stocks (TOC), in humic substance fractions (fulvic acids, humic and humin) and total (humic substances) in layers of $0-0.10 ; 0.10-0.20 ; 0.20-0.40 ; 0.40-0.60 ; 0.60-$ 1 and $0-1 \mathrm{~m}$ of soil samples collected at lines (EL) and interlines (EEL) of eucalypt and pasture (P). Means followed by the same letter do not differ at $5 \%$ by LSD test. ${ }^{*}$, ns: significant at $5 \%$ and not significant $(\mathrm{P}>5 \%)$ for cultivation, the $\mathrm{F}$ test of ANOVA.

Ci. Fl., v. 21, n. 2, abr.-jun., 2011 


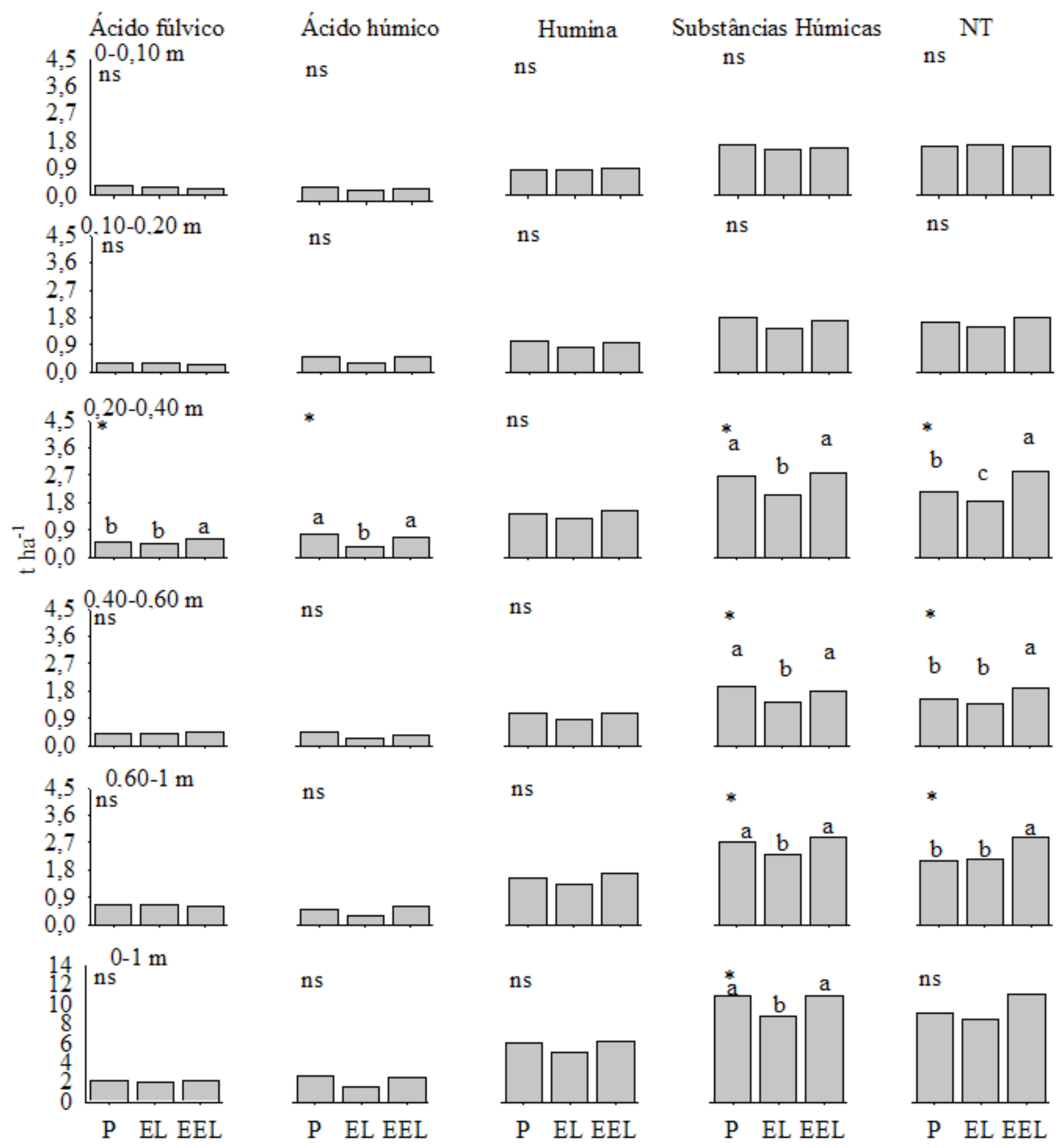

FIGURA 2: Estoques de nitrogênio total (NT), nas frações das substâncias húmicas (ácidos fúlvicos, húmicos e húminas) e total (substâncias húmicas) nas camadas de $0-0,10 ; 0,10-0,20 ; 0,20$ 0,$40 ; 0,40-0,60 ; 0,60-1$ e $0-1 \mathrm{~m}$ de solo, em amostras coletadas nas linhas (EL) ou entrelinhas (EEL) do eucalipto e pastagem (P). Médias seguidas da mesma letra minúscula não diferem entre si a 5\% pelo teste LSD. *, ns: respectivamente significativo a 5\% e não significativo (P > $5 \%$ ) para cultivos, pelo teste $\mathrm{F}$ da ANOVA.

FIGURE 2: Total nitrogen stocks (TN), in humic substance fractions (fulvic acids, humic and humin) and total (humic substances) in layers of $0-0.10 ; 0.10-0.20 ; 0.20-0.40 ; 0.40-0.60 ; 0.60-1$ and $0-1 \mathrm{~m}$ of soil samples collected at lines (EL) and interlines (EEL) of eucalypt and pasture (P). Means followed by the same letter do not differ at $5 \%$ by LSD test. ${ }^{*}$, ns: significant at $5 \%$ and not significant $(\mathrm{P}>5 \%)$ for cultivation, the $\mathrm{F}$ test of ANOVA. 


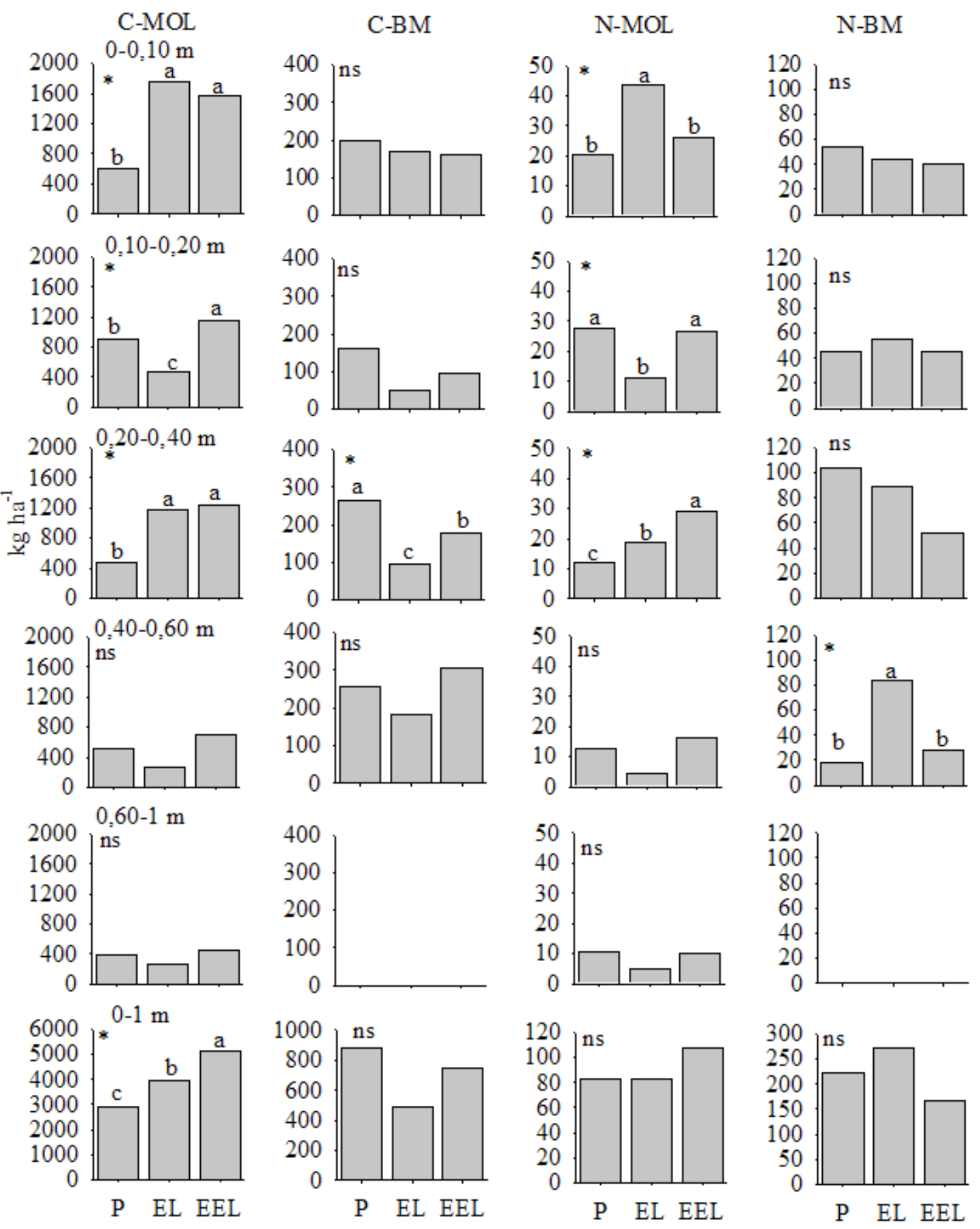

FIGURA 3: Estoques de $\mathrm{C}$ e $\mathrm{N}$ na fração leve (C-MOL e N-MOL) e na biomassa microbiana (C-BM and N-BM) nas camadas de $0-0,10 ; 0,10-0,20 ; 0,20-0,40 ; 0,40-0,60 ; 0,60-1$ e $0-1 \mathrm{~m}$ de solo, em amostras coletadas nas linhas (EL) ou entrelinhas (EEL) do eucalipto e pastagem (P). Médias seguidas da mesma letra minúscula não diferem entre si a 5\% pelo teste LSD. *, ${ }^{*}$ : respectivamente significativo a 5\% e não significativo ( $\mathrm{P}>5 \%$ ) para cultivos, pelo teste $\mathrm{F}$ da ANOVA.

FIGURE 3: Carbon and nitrogen stocks in light fraction (C-MOL e N-MOL) and microbial biomas (C$\mathrm{BM}$ and N-BM) in layers of $0-0.10 ; 0.10-0.20 ; 0.20-0.40 ; 0.40-0.60 ; 0.60-1$ and $0-1 \mathrm{~m}$ of soil samples collected at lines (EL) and interlines (EEL) of eucalypt and pasture (P). Means followed by the same letter do not differ at $5 \%$ by LSD test. ${ }^{*}$, ns: significant at $5 \%$ and not significant $(\mathrm{P}>5 \%)$ for cultivation, the $\mathrm{F}$ test of ANOVA.

Ci. Fl., v. 21, n. 2, abr.-jun., 2011 
Os estoques de $\mathrm{N}$ nas substâncias húmicas na camada de $0-1 \mathrm{~m}$ na entrelinha de eucalipto e da pastagem foram de, aproximadamente, $11 \mathrm{t} \mathrm{ha}^{-}$ 1 , enquanto na linha do eucalipto, o estoque foi de, aproximadamente, 9 t ha $^{-1}$ (Figura 2). Nessa condição, possivelmente a maior deposição de resíduos da parte aérea e radicular do eucalipto na entrelinha, o estoque de $\mathrm{C}$ pelo sistema radicular da pastagem e, possivelmente, a menor relação $\mathrm{C} / \mathrm{N}$ no resíduo da pastagem (fração leve $\approx 35$ ) deposto ao longo do tempo no solo, contribuiram para o maior acúmulo de $\mathrm{N}$ nas substâncias húmicas em relação ao solo cultivado com eucalipto com menor abundância de resíduos vegetais no solo (fração leve $\approx$ 50). Stevenson (1994) destacou a essencialidade do N na síntese de substâncias húmicas. Evidências sugerem que ele tem importante papel na humificação e formação de compostos orgânicos estáveis no solo (DIJKSTRA et al., 2004). Incrementos de $\mathrm{N}$ no solo podem reduzir a produção de enzimas (lignolíticas) que atuam no processo de decomposição microbiana (CARREIRO et al., 2000) e aumentar a estabilização estrutural das substâncias húmicas em virtude da reação do N (amônio e nitrato) com resíduos de lignina e compostos fenólicos, seguido pela formação de compostos recalcitrantes como, por exemplo, um complexo tanino-proteína (SJÖBERG et al., 2004).

Na camada de $0-1 \mathrm{~m}$, os estoques de COT foram superiores na entrelinha do eucalipto em comparação aos outros tratamentos, e o estoque de $\mathrm{N}$ total, nessa mesma camada de solo foi semelhante entre a pastagem e o eucalipto (Figuras 1 e 2). Em média, verificaramse valores de 120 e $100 \mathrm{t} \mathrm{ha}^{-1}$ de $\mathrm{C}$, respectivamente, na entrelinha do eucalipto e na pastagem, que foi semelhante ao estoque de $\mathrm{C}$ na linha do eucalipto. Para $\mathrm{N}$, foram quantificados $10 \mathrm{t} \mathrm{ha}^{-1} \mathrm{em}$ ambos os solos cultivados. Tais estoques foram pouco inferiores aos encontrados por Sisti et al. (2004), estudando solos de cultivos anuais (soja, trigo e milho) na Região Sul do Brasil, em semeadura direta e convencional onde obtiveram estoques médios de 175,2 e 163,8 $\mathrm{t} \mathrm{ha}^{-1}$ de C e 14,6 e 13,4 t ha ${ }^{-1}$ de N. Binkley et al. (2004) encontraram em plantações de eucalipto em primeira rotação, no Hawaii, estoque médio de $13,5 \mathrm{~kg} \mathrm{~m}^{-2}$ (135 t ha $\left.^{-1}\right)$ de C no solo após 8 anos de cultivo, nos primeiros $0,45 \mathrm{~m}$ de profundidade. Batjes (2005), ao avaliar os estoques de $\mathrm{C}$ nos principais solos do Brasil obtive variações de $42 \mathrm{t} \mathrm{h}^{-1}$ para Neossolos Quartzarênicos a $137 \mathrm{t} \mathrm{ha}^{-1}$ para Gleissolos na mesma camada de solo (0-1 m). E, Lima et al. (2006) comparando cultivos de eucalipto de curta rotação de 7 anos (com 32 anos de cultivo) com pastagem cultivada, na camada de 0-0,10 $\mathrm{m}$ de solo, verificaram aumentos de 21,5\% (4,47 $\left.\mathrm{tha}^{-1}\right)$ e $21,7 \%\left(6,8 \mathrm{t} \mathrm{ha}^{-1}\right)$ respectivamente na região de Belo Oriente e Virginópolis no estado de Minas Gerais, o que corroborou com os resultados encontrados no presente estudo (Figura 1).Nesse sentido, observou-se que os estoques de $\mathrm{C}$ nos ecossistemas podem variar muito, de acordo com o tipo de solo, clima, vegetação e manejo (MANN, 1986).

Alterações na qualidade de serapilheira aportada no solo também podem ter contribuído para as diferenças nos estoques totais de $\mathrm{C}$ e $\mathrm{N}$ no solo de pastagem e na entrelinha do eucalipto. De modo geral, verificam-se diferenças de natureza física e química da serapilheira depositada pelo eucalipto, onde materiais mais grosseiros e mais lignificados são depositados em maior quantidade do que em pastagens (PEGORARO, 2007), que são resíduos que apresentam menor conteúdo de lignina e tanino estando mais suscetíveis à decomposição microbiana que a serapilheira originária do eucalipto (MENDHAM et al., 2004). Além disso, a taxa de decomposição pode ser predita pela relação $\mathrm{C} / \mathrm{N}$ ou simplesmente pela concentração de $\mathrm{N}$ na serapilheira (SARIYILDIZ e ANDERSON, 2003).

No presente estudo, verificou-se menor relação $\mathrm{C} / \mathrm{N}$ na serapilheira do cultivo de pastagem (pastagem $=56,37$ e eucalipto $=93,04$ ), indicando a maior labilidade desse resíduo. Consequentemente, a serapilheira da pastagem pode ser decomposta mais rapidamente que aquela de eucalipto, como o volume de resíduos aportados no solo de pastagem foi menor, pode ter ocorrido maior decomposição da MOS nativa, ou seja, na falta de C-lábil proveniente de resíduos vegetais, os microrganismos passam a consumir $\mathrm{C}$ originário da MOS (nativo), causando redução no seu teor. Embora o resíduo de eucalipto tenha apresentado menor qualidade (maior relação $\mathrm{C} / \mathrm{N}$ em razão dos resíduos mais grossos), possivelmente, seu maior aporte na entrelinha de cultivo, juntamente com a lenta decomposição microbiana podem justificar o aumento nos estoques de $\mathrm{C}$ no solo cultivado com eucalipto. Mendham et al. (2004) verificaram menor teor de $\mathrm{N}$ e taxa de decomposição da MOS em cultivos de eucalipto em comparação à pastagem, o que auxiliou no aumento do teor de $\mathrm{C}$ da fração particulada, mesmo assim, os teores totais de $\mathrm{C}$ na MOS foram semelhantes. Notoriamente, tem-se obtido incrementos significativos de $\mathrm{C}$ em cultivos de eucalipto sob solos de pastagem tropicais e, com o aumento do tempo de cultivo florestal (ZINN et al., 2002; LIMA et al., 2006), possivelmente pela má condição de conservação e produtividade das pastagens.

$\mathrm{Na}$ área de cultivo de eucalipto, o acúmulo e posterior enterrio dos resíduos da colheita propiciaram 
Pegoraro, R. F. et al.

o incremento de 30 e $2,5 \mathrm{t} \mathrm{ha}^{-1}$ de $\mathrm{C}$ e $\mathrm{N}$ total em comparação ao solo de eucalipto sem a deposição dos resíduos da colheita (EL). Além disso, frações da MOS consideradas mais estáveis (humificadas) também foram favorecidas, com incrementos de $2 \mathrm{t} \mathrm{ha}^{-1}$ de $\mathrm{N}$ nas sustâncias húmicas e $7 \mathrm{t} \mathrm{ha}^{-1}$ de $\mathrm{C}$ na fração ácidos húmicos na camada de $0-1 \mathrm{~m}$.

\section{Estoques de carbono e nitrogênio na fração leve e na biomassa microbiana}

$\mathrm{O}$ maior estoque de $\mathrm{C}$ da biomassa microbiana (C-BM) na camada de 0-0,60 $\mathrm{m}$ de profundidade foi observado no solo de pastagem $\left(879 \mathrm{~kg} \mathrm{ha}^{-1}\right)$, que foi semelhante ao da entrelinha do eucalipto (EEL) $(741 \mathrm{~kg}$ $\left.\mathrm{ha}^{-1}\right)$, que, por sua vez, foram superiores ao verificado na linha do eucalipto (EL) (492 $\left.\mathrm{kg} \mathrm{ha}^{-1}\right)$. Já para o $\mathrm{N}$, essas diferenças não foram observadas (Figura 3). A maior distribuição de raízes de pastagem, sobretudo de raízes finas no perfil do solo em cultivo com pastagem incrementando a liberação de compostos solúveis pela exudação ou decomposição radicular, facilmente utilizáveis como fonte de energia pelos microorganismos (KUZYAKOV e DOMANSKI, 2000), e o maior aporte de resíduos na entrelinha do solo de eucalipto podem ter contribuído para maiores estoques de $\mathrm{C}$ na biomassa microbiana. $\mathrm{O} \mathrm{C}$ total e da biomassa microbiana apresentam significativa correlação, assim como para $\mathrm{C}$ solúvel em água, $\mathrm{C}$ da fração leve correlacionado com o CBM. (HAYNES, 2000) e Mendham etal. (2002) verificaram correlações positivas entre os conteúdos de $\mathrm{C}$ e $\mathrm{N}$ da biomassa microbiana com os de $\mathrm{C}$ orgânico e $\mathrm{N}$ total no solo. Além disso, o C-BM aumentou na presença de resíduos da colheita na superfície de solos cultivados com Eucalyptus globulus, no primeiro e aos cinco anos após o seu estabelecimento no sudoeste da Austrália (MENDHAM et al., 2002).

Com base nos resultados obtidos, pode-se inferir que o cultivo de eucalipto apresentou incremento positivo nos estoques de $\mathrm{C}$ e $\mathrm{N}$ nas camadas superficiais do solo $(0-0,10 ; 0,10-0,20$ e $0,20-0,40 \mathrm{~m})$ para a maioria dos parâmetros avaliados, sobretudo na entrelinha de plantio, indicando uma possível sustentabilidade do solo para esse ecossistema em relação à pastagem. Paul et al. (2002) encontraram aumento do teor de $\mathrm{C}$ na camada de 0-0,30 $\mathrm{m}$ de solo para cultivos de eucalipto em relação à pastagem. Guo e Gifford (2002) não observaram, em sua revisão, nenhuma mudança no estoque de $\mathrm{C}$ total no solo após substituição de pastagem pelo cultivo de eucalipto. Já Davis e Condron (2002) ressaltaram que a substituição de pastagens por florestas plantadas geralmente leva à redução nos teores de matéria orgânica do solo. A controvérsia de resultados, possivelmente, está associada à grande variabilidade de condições ambientais, tipo de cultivo adotado e o tempo de substituição dessas pastagens. Em solos de pastagens degradadas do Brasil, o cultivo de eucalipto de curta rotação (7 a 8 anos) (Leite et al., 2001) e o aumento do tempo de cultivo (LIMA et al., 2006) têm aumentado os estoques totais de $\mathrm{C}$ no solo. $\mathrm{Na}$ última condição, substanciais incrementos de $\mathrm{C}$ $\left(0,8 \mathrm{~kg} \mathrm{~m}^{-2}\right)$ na camada superficial do solo $(0-0,10 \mathrm{~m})$ foram obtidos após duas rotações (14 anos) de cultivos de eucalipto sob solo de pastagem, e com três ou quatro rotações esses incrementos foram estabilizados em valores maiores que a pastagem que o precedeu, porém, ainda em valores abaixo do observado para solos sob vegetação de mata nativa (Mata Atlântica).

\section{Contribuição do cultivo de eucalipto para o estoque de carbono do solo em substituição à pastagem}

A contribuição de plantas $\mathrm{C}_{3}$ para a MOS no cultivo de eucalipto foi da ordem de 76 e $84 \%$ e, de plantas $\mathrm{C}_{4}$ da ordem de 24 e $16 \%$, respectivamente, na linha e entrelinha na camada de $0-0,20 \mathrm{~m}$ de solo (Tabela 1). Ao subtrair-se o $\mathrm{C}-\mathrm{C}_{3}$ derivado de plantas de mata nativa (47\%), remanescente no solo de pastagem (início do plantio do eucalipto) daquele de plantas $\mathrm{C}_{3}$ após 28 anos (quatro rotações) de cultivo do eucalipto, obteve-se a proporção de MOS derivada do eucalipto (plantas $\mathrm{C}_{3}$ ) em 29 e 37\%, respectivamente, na linha e entrelinha. Tais valores indicam que a taxa de ciclagem média da MOS nesse solo foi da ordem de 1,18\% ao ano, 1,04 e $1,32 \%$ ao ano, respectivamente, na linha e entrelinha do eucalipto. A diferença observada entre o $\% \mathrm{C}-\mathrm{C}_{3}$ da linha e entrelinha $(8 \%)$ reflete a maior deposição de resíduos vegetais na entrelinha do eucalipto.

Em Latossolo argiloso na região de Cerrado de Uberlândia, MG, verificou-se uma taxa média anual de substituição da ordem de $1,5 \%$ correspondendo no final de 20 anos de cultivo a uma substituição de $30 \%$ do C original do solo de Cerrado pelo C derivado de Pinus sp. (WILCKE e LILLENFEIN, 2004). Lima et al. (2006) observaram, em cultivo do eucalipto por 32 anos (quatro rotações,) taxas médias anuais de substituição do $\mathrm{C}$ da ordem de 0,43, 0,40 e 0,20\% para as camadas de 0-5, 5-10 e 10-20 cm de profundidade, respectivamente, em Latossolo com textura argilosa na região de Virginópolis. Essa variação na taxa de ciclagem da MOS nos cultivos de eucalipto podem estar associados às distintas condições de manejo do solo, tipo de solo (quantidade e qualidade e argila) clima e altitude de cada região estudada (ZINN et al., 2005). Na região norte do estado do Espírito Santo, onde esteve localizado o estudo de estoques de carbono e nitrogênio, observa- 
TABELA 1: Abundância natural de ${ }^{13} \mathrm{C}$ e contribuição relativa de plantas $\mathrm{C} 3$ e $\mathrm{C} 4$ para a matéria orgânica de solos cultivados com eucalipto e pastagem na camada de solo de $0-0,20 \mathrm{~m}$ de profundidade.

TABLE 1: Natural abundance of ${ }^{13} \mathrm{C}$ and relative contribution of $\mathrm{C}_{3}$ and $\mathrm{C}_{4}$ plants for organic matter in soils cultivated with eucalypt and grass in the soil layer $0-0.20 \mathrm{~m}$ depth.

\begin{tabular}{ll|c|c|c|c|c}
\hline \multirow{2}{*}{ Cultivos } & \multirow{2}{*}{ Coleta } & Estoque de & $\delta^{13} \mathrm{C}(\mathrm{V}-\mathrm{PDB})$ & \multicolumn{2}{c|}{$\delta^{13} \mathrm{C}(\mathrm{V}-\mathrm{PDB})$} & \multicolumn{2}{c}{ Contribuição } \\
\cline { 7 - 8 } & & $\mathrm{C}\left(\mathrm{t} \mathrm{ha}^{-1}\right)$ & Solo & Mat. Vegetal & $\mathrm{C} 3(\%)$ & $\mathrm{C} 4(\%)$ \\
\hline \multirow{2}{*}{ Eucalipto (E) } & Entrelinha & 23,10 & $-26,05$ & $-27,40$ & 84 & 16 \\
Pastagem (P) & Linha & 18,27 & $-25,42$ & $-27,40$ & 76 & 24 \\
\hline & Total & 17,79 & $-19,13$ & $-12,70$ & 47 & 53 \\
\hline
\end{tabular}

se a presença de solos com textura média, o que pode conferir menor proteção física aos complexos organominerais e contribuir substancialmente para a exposição MOS à decomposição microbiana, aumentanto a taxa de ciclagem de $\mathrm{C}$ orgânico no solo, especialmente quando comparado a outras regiões com maior altitude e solos mais argilosos, como no caso daquela de Virginópolis, MG.

$\mathrm{O}$ aumento na taxa de ciclagem de $\mathrm{C}$ de eucalipto na entrelinha em comparação ao solo da linha de cultivo também ocorreu concomitantemente ao incremento do estoque de $\mathrm{C}$ orgânico na camada superficial 0-0,20m (Figura 4), mesmo ao serem consideradas as perdas de $\mathrm{C}-\mathrm{C}_{3}$ pela substituição de cultivos (pastagem por eucalipto). Após 28 anos de cultivo, verificaram-se estoques médios de 11,0 e 5,5 t ha ${ }^{-1}$ de carbono derivado, respectivamente, de eucalipto na entrelinha e linha, correspondendo à taxa média de acúmulo de $\mathrm{C}$ orgânico no solo de 0,39 e $0,20 \mathrm{t} \mathrm{ha}^{-1}$ ano ${ }^{-1}$. Ao assumir-se que as perdas de carbono orgânico derivado da mata nativa foram ínfimas (carbono remanescente de décadas de cultivo, considerado recalcitrante), pode-se inferir que a taxa de acúmulo de carbono orgânico derivado de plantas $\mathrm{C}_{3}$ (eucalipto) foi superior as perdas de carbono derivado da pastagem $\left(\mathrm{C}_{4}\right)$ no solo da entrelinha $\left(0,21 \mathrm{tha}^{-1}\right.$ ano $\left.^{-1}\right)$ e na linha $(0,18 \mathrm{t}$ $\left.\mathrm{ha}^{-1} \mathrm{ano}^{-1}\right)$, sobretudo na primeira. Tais valores reforçam a hipótese de que o aumento da deposição de resíduos de eucalipto provenientes da parte aérea, cepas e raízes podem contribuir substancialmente para o aumento da MOS, e não somente para a substituição do C nativo do solo.
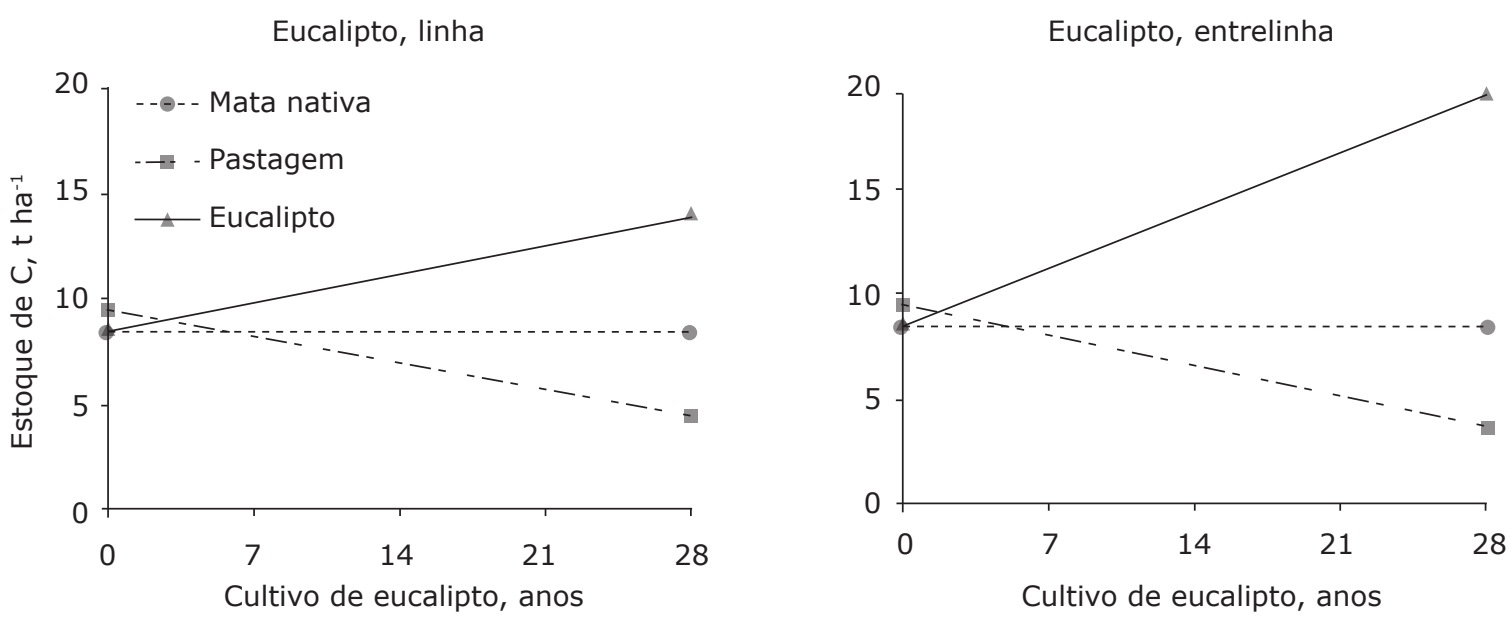

FIGURA 4: Estoque de carbono orgânico do solo derivado de plantas $\mathrm{C}_{3}$ (eucalipto) e $\mathrm{C}_{4}$ (pastagem) durante 28 anos de cultivo de eucalipto em amostras de solos coletadas na linha e entrelinha para a camada de $0-0,20 \mathrm{~m}$. Barras de erro-padrão não foram mostradas, pois os valores são médias de amostras compostas analizadas.

FIGURE 4: Soil organic carbon stock derived from $\mathrm{C}_{3}$ (eucalypt) and $\mathrm{C}_{4}$ (pasture) plants during 28 years of eucalyptus cultivation in soil samples collected at the line and interline for the $0-0.20 \mathrm{~m}$ soil layer. Standard deviation bars are not shown because the values are means of a composite sample analyzed. 


\section{CONCLUSÕES}

A incorporação de resíduos da colheita do eucalipto na atual entrelinha aumenta o estoque de carbono orgânico total, e fração leve nas primeiras camadas do solo (até $0,60 \mathrm{~m}$ ) e, nas substâncias húmicas para as camadas de 0,20-0,40 e 0,40-0,60 $\mathrm{m}$, em comparação ao solo sob pastagem e à linha de plantio ao final do ciclo de cultivo do eucalipto.

O eucalipto, após 28 anos (quatro rotações) de cultivo apresenta taxa média de ciclagem da MOS de $1,18 \%$, o que corresponde ao incremento anual de 0,39 e 0,20 tha $^{-1}$ de carbono orgânico derivado de plantas $\mathrm{C}_{3}$ de eucalipto, respectivamente, na entrelinha e linha de cultivo.

$\mathrm{Na}$ camada de $0-1 \mathrm{~m}$ o estoque de carbono orgânico total é semelhante entre o solo da linha de plantio do eucalipto e o de pastagem, e inferiores ao solo da entrelinha do eucalipto. Para as frações ácidos fúlvicos, húmicos e fração leve o estoque de carbono no solo sob cultivo de eucalipto é superior, mas o solo sob pastagem e entrelinha de eucalipto têm maior estoque de nitrogênio nas substâncias húmicas do que o solo da linha de eucalipto.

\section{AGRADECIMENTOS}

À FAPEMIG, ao CNPq, pelo apoio financeiro aos autores do estudo. À empresa florestal Aracruz, pela disponibilização da área experimental para realização do estudo.

\section{REFERÊNCIAS BIBLIOGRÁFICAS}

ALCÂNTARA, F. A. et al. Conversion of grassy cerrado into riparian forest and its impact on soil organic matter dynamics in an Oxisol from southeast Brazil. Geoderma, Amsterdam, v. 123, n. 3-4, p. 305-317, 2004.

BATAGLIA, O. C. et al. Métodos de análises químicas de plantas. Campinas: Instituto Agronômico, 1983. 48 p. (Boletim, 78)

BATJES, N. H. Organic carbon stocks in the soils of Brazil. Soil Use and Management, Stirling, v. 21, n. 1, p. 22-24, Mar, 2005.

BINKLEY, D.; RESH, S. C. Rapid changes in soils following eucalyptus afforestation in Hawaii. Soil Science Society of America Journal, Madison, v. 63 , n. 1, p. 222-225, 1999

BINKLEY, D. et al. First-rotation changes in soil carbon and nitrogen in a Eucalyptus plantation in Hawaii. Soil Science Society of America Journal,
Madison, v. 68, n. 5, p. 1713-1719, 2004.

Carreiro, M. M. et al. Microbial enzyme shifts explain litter decay responses to simulated nitrogen deposition. Ecology, Washington, v. 81, n. 9, p. 2359-2365, 2000.

DAVIS, M.; CONDRON, L. Impact of grassland afforestation on soil carbon in New Zealand: a review of paired-sites studies. Australian Journal of Soil Research, Collingwood, v. 40, n. 4, p.675690, 2002.

DIJKSTRA, F. A. et al. Nitrogen deposition and plant species interact to influence soil carbon stabilization. Ecology Letters, Oxford, v. 7, n. 12, p. 1192-1198, 2004.

FUNDAÇÃO ARTHUR BERNARDES FUNARBE. SAEG - Sistema para análise estatística 5.0. Viçosa, 1993.

GUO, L. B.; GIFFORD, R. M. Soil carbon stocks and land use change: a meta analysis. Global Change Biology, Oxford, v. 8, n. 4, p. 345-360, 2002.

HAYNES, R. J. Labile organic matter as an indicator of organic matter quality in arable and pastoral soils in New Zealand. Soil Biology and Biochemical, Oxford, v. 32, n. 2, p. 211-219, 2000.

ISLAM, K. R.; WEIL, R. R. Microwave irradiation of soil for routine measurement of microbial biomass carbon. Biology and Fertility of Soils, Berlin, v. 27, n. 4, p. 408-416, 1998.

KUZYAKOV, Y.; DOMANSKI, G. Carbon input by plants into the soil. Review. Journal of Plant Nutrition and Soil Science, Weinheim, v.163, n. 4, p. 421-431, 2000.

LEITE, F. P. Relações nutricionais e alterações de características químicas de solos da Região do Vale do Rio Doce pelo cultivo do eucalipto. 2001, 72 f. Tese (Doutorado em Solos e Nutrição de Plantas)-Universidade Federal de Viçosa, Viçosa, 2001.

Lemma, B. et al. Decomposition and substrate quality of leaf litters and fine roots from three exotic plantations and a native forest in the southwestern highlands of Ethiopia. Soil Biology and Biochemical, Oxford, v. 39, n. 9, p. 2317-2328, 2007.

LILIENFEIN, J.; WILCKE, W. Element storage in native, agri-, and silvicultural ecosystems of the Brazilian savanna - I. Biomass, carbon, nitrogen, phosphorus, and sulfur. Plant and Soil, Dordrecht, v. 254, n. 2, p. 425-442, 2003.

LIMA, A. M. N. Estoques de carbono e frações da matéria orgânica do solo sob povoamentos 
de eucalipto no vale do rio doce - MG. 2004. 72 f. Dissertação (Mestrado em Solos e Nutrição de Plantas)-Universidade Federal de Viçosa, Viçosa, 2004.

LIMA, A. M. N. et al. Soil organic carbon dynamics following afforestation of degraded pastures with eucalyptus in southeastern Brazil. Forest Ecology and Management, Amsterdam, v. 235, n. 1-3, p. 219-231, 2006.

MANN, L. K. Changes in soil carbon storage after cultivation. Soil Science, Baltimore, v. 142, n. 5, p. 279-288, 1986.

MENDHAM, D. S. et al. Soil particulate organic matter effects on nitrogen availability after afforestation with Eucalyptus globules. Soil Biology and Biochemical, Oxford, v. 36, n. 1, p. 1067-1074, 2004.

MENDHAM, D. S. et al. Organic matter characteristics under native forest, long-term pasture, and recent conversion to eucalyptus plantations in Western Australia: microbial biomass, soil respiration, and permanganate oxidation. Australian Journal of Soil Research, v. 40, n. 5, p. 859-872, 2002.

NEUFELDT, $H$. et al. Texture and land-use effects on soil organic matter in Cerrado Oxisols, Central Brazil. Geoderma, Amsterdam, v. 107, n. 3-4, p. 151-164, 2002.

OMETTO, J. C. Bioclimatologia vegetal. São Paulo, Ceres, 1981. 425 p.

PAUL, K. I. et al. Change in soil carbon following afforestation. Forest Ecology and Management, Amsterdam, v. 168, n. 1-3, p. 241-257, 2002.

PEGORARO, R. F. Seqüestro de carbono e alterações bioquímicas da matéria orgânica de solos cultivados com eucalipto. 2007. $140 \mathrm{f}$. Tese (Doutorado em Solos e Nutrição de Plantas)Universidade Federal de Viçosa, Viçosa, 2007.

RASSE, D. P. et al. Is soil carbon mostly root carbon? Mechanisms for a specific stabilization. Plant and Soil, Dordrecht, v. 269, n. 1-2, p. 341356, 2005.

ROVIRA, P.; VALLEJO, V. R. Labile and recalcitrant pools of carbon and nitrogen in organic matter decomposing at different depths in soil: an acid hydrolysis approach. Geoderma, Amsterdam, v. 107, n. 1-2, p. 109-141, 2002.

SARIYILDIZ, T.; ANDERSON, J.M. Decomposition of sun and shade leaves from three deciduous tree species, as affected by their chemical composition. Biology and Fertility of Soils, Berlin, v. 37, n. 3, p. 137-146, 2003.

SILVER, W. L. et al. The potential for carbon sequestration through reforestation of abandoned tropical agricultural and pasture lands. Restoration ecology, Malden, v. 8, n. 4, p. 394-407, 2000.

SISTI, C. P. J. et al. Change in carbon and nitrogen stocks in soil under 13 years of conventional or zero tillage in southern Brazil. Soil and Tillage Research, Amsterdam, v. 76, n. 1, p. 39-58, 2004. SJÖBERG, G. et al. Impact of long-term N fertilization on the structural composition of spruce litter and mor humus. Soil Biol. Biochem., v. 36, p. 609-618, 2004.

SOHI, S. P. et al. A procedure for isolating soil organic matter fractions suitable for modeling. Soil Science Society of America Journal, Madison, v. 65, n.4, p. 1121-1128, 2001.

STEEL, R. G. D. et al. Principles and procedures of statistics: a biometrical approach. New York: McGraw-Hill, 1997. 666 p.

STEVENSON, F.J. Humus Chemistry: Genesis, Composition and Reactions. $2^{\text {nd }}$ ed. New York, Willey \& Sons Inc., 1994. 496 p.

SWIFT, R. S. Method for extraction of IHSS soil fulvic and humic acids. In. SPARKS, D. L. et al.(Eds.) Methods of soil analysis. Part 3. Chemical methods. Soil Sci. Soc. Am. Books, 1996. p. 1018-1020.

VITORELLO, V. A. et al. Organic matter and natural carbon-13 distribution in forested and cultivated Oxisols. Soil Science Society of America Journal, Madison, v. 53, n. 3, p. 773-778, 1989.

WILCKE, W.; LILIENFEIN, J. Soil carbon-13 natural abundance under native and managed vegetation in Brazil. Soil Science Society of America Journal, Madison, v. 68, n. 3, p. 827-832, 2004.

YEOMANS, J. C.; BREMNER, J. M. A rapid and precise method for routine determination of organic carbon in soil. Communications in Soil Science and Plant Analysis, Philadelphia, v. 13, n. 13, p. 1467-1476, 1988.

ZINN, Y. L. et al. Changes in soil organic carbon stocks under agriculture in Brazil. Soil and Tillage Research, Amsterdam, v. 84, n.1, p. 28-40, 2005.

ZINN, Y. L. et al. Soil organic carbon as affected by afforestation with Eucalyptus and Pinus in the Cerrado region of Brazil. Forest Ecology and Management, Amsterdam, v. 166, n. 1-3, p. 285$294,2002$. 